Fecha de recepción: febrero 2020 Fecha de aceptación: marzo 2020 Versión final: abril 2020

\section{Mulheres editoras independentes: Constanza Brunet (Argentina) Maria Mazarello (Brasil) e Paula Anacaona (França) e as projeções de si}

Letícia Santana Gomes ${ }^{(1)}$ e Giani David Silva ${ }^{(2)}$

\begin{abstract}
Resumo: Pretendemos analisar o discurso autobiográfico de três editoras de livros independentes, mulheres, em uma posição de criadoras de suas casas editoriais e formadoras do próprio catálogo. Por meio do discurso de Constanza Brunet (Marea Editorial - Argentina), Maria Mazarello (Mazza Edições - Brasil) e Paula Anacaona (Anacaona Edições França), pretendemos encontrar as projeções de si e a ideia do trabalho como algo íntimo e indissociável do ser humano.
\end{abstract}

Palavras chave: Mulheres editoras independentes - Mercado Editorial - Ethos discursivo Maria Mazarello - Constanza Brunet - Paula Anacaona.

[Resumos em espanhol e inglês nas páginas 110-111]

(1) Doutoranda e Mestre em Estudos de Linguagens pelo Centro Federal de Educação Tecnológica de Minas Gerais (CEFET-MG), onde também se bacharelou em Letras (Tecnologias de Edição), é também licenciada em Letras - Língua Portuguesa. Tem experiência de estudos sobre mercado editorial, com destaque aos(às) editores(as) independentes. Atualmente, é pesquisadora no CEFET-MG.

(2) Doutora em Estudos Linguísticos pela Universidade Federal de Minas Gerais (2005). Realizou Estágio Doutoral na Université de Paris XIII (2001). Atualmente é professora do Centro Federal de Educação Tecnológica de Minas Gerais (CEFET-MG) onde atua como membro permanente do Programa de Pós-graduação Stricto Sensu em Estudos de Linguagens e como professora do Curso de Letras e do Ensino Técnico e Tecnológico.

\title{
Introdução
}

Diante das inúmeras postulações que esse signo "independente" e, sobretudo, "editora" suscita, nos questionamos: o que seria o signo emblemático "editora"? A representação de uma mulher como responsável pela edição de uma obra? Ou a casa editorial, instituição, propriamente dita? E a mulher editora independente, como se projeta diante dessas 
adjetivações? Por isso, pretendemos levantar alguns questionamentos até então pouco discutidas no cenário editorial e na Análise do Discurso, sobretudo nos discursos autobiográficos.

Quais foram as mulheres no cenário editorial que estavam à frente de suas casas editoriais? Quem são essas mulheres que levam publicações a um público diverso de leitores? Quem são essas editoras, mulheres, que se autointitulam independentes? De que maneira os papéis sociais desempenhados pelas editoras ditas independentes se entrecruzam em suas narrativas de vida? Percebemos que, o sujeito falante, ao contar sobre sua própria vida, não consegue desvinculá-la sem fazer menção ao trabalho. A profissão, portanto, é indissociável de sua vida íntima, privada, como uma forma de autoconstrução desse sujeito. Outra questão também é colocada diante desse questionamento: ao narrar sobre sua própria vida, tais editoras não fazem uma edição de si?

Isso nos instiga pelo fato de que não contamos sempre a mesma história, mesmo que evoquemos os mesmos acontecimentos: cada vez, a situação de enunciação, o gênero discursivo escolhido e o outro, o interlocutor, vai impor uma forma de relato, que é, justamente, o que fará sentido. Por isso, na dinâmica do narrar, entre o pessoal e o coletivo, a tentativa de nomear aquilo que se vê, a possibilidade e a impossibilidade da transmissão, de dar conta da própria experiência, se transforma em narrativas e em múltiplas faces do dizer. Por isso a ideia de relacionar o discurso das editoras independentes dentro de um espaço biográfico e pensar em categorias analíticas que envolvam as narrativas de vida, a Análise do Discurso e os processos editoriais. Com a impossibilidade de definir com apenas um adjetivo - independente - essas editoras, decidimos que a escuta atenta a elas e as especificidades sobre o que é ser independente aproximaria da imagem que tem de sua própria profissão e de si (Muniz Jr., 2016). Para isso, selecionamos as seguintes editoras, dentre outros motivos, i) Maria Mazarello, no Brasil, uma das primeiras editoras de com publicações voltadas à temática afro-brasileira, há quase 40 anos realizando um pioneiro trabalho editorial; ii) Constanza Brunet, na Argentina; poderíamos indicar como o maior nome de editora cuja temática é progressiva no país, com publicações exclusivas de jornalismo investigativo e história política e, por fim, iii) Paula Anacaona, na França, especializada em editar apenas obras literárias brasileiras consideradas marginalizadas. Essas especificidades de cada uma das editoras nos fizeram reuni-las e obter um registro de suas narrativas, a fim de contribuir para um acervo ainda pouco discutido sobre mulheres que editam.

\section{O contexto editorial}

Todas as editoras selecionadas são reconhecidas pela especificidade na produção e difusão literária, e isso se deve ao fato, sobretudo, de serem mulheres em uma posição de criadoras de suas casas editoriais, como já mencionado, e pela representatividade que a Argentina, o Brasil e a França assumem no contexto editorial - embora existam contrastes significativos editorialmente nesses países (cultura, língua, investimentos), é necessário situarmos o papel de difusão de obras, autores, editores, que se tornaram legitimados em todo mundo nesses lugares. Certamente, essas editoras buscam que as publicações de suas editoras pos- 
sam chegar em outros territórios, não apenas para os lugares de origem. Ademais, o critério de interculturalidade, como intercâmbio cultural entre as sociedades, prevalecendo a diversidade entre eles, sustenta a justificativa para essas escolhas.

A França, com destaque para Paris, impôs sua hegemonia cultural desde o fim do século XIX. Conforme destaca Casanova (2002), alguns critérios foram estabelecidos para tal afirmação, com os "indicadores culturais", sendo analisados a quantidade de livros publicados todos os anos e qual a margem de venda; o tempo de leitura por habitante; os subsídios aos escritores, como também o número de editores, de livrarias; o espaço reservado aos livros na imprensa, o tempo dedicado aos livros nos programas de televisão; e até mesmo o número de ruas com o nome de um escritor famoso. Diante desses indicadores, Paris é onde se concentram e se acumulam os recursos literários, a capital literária, e, como ressaltou o poeta Valéry, a cidade é uma função necessária da estrutura literária. A capital combina as características antitéticas, reunindo as representações de liberdade, simboliza a Revolução, o fim da monarquia e é, também, a capital intelectual, fundadora da democracia política e da liberdade artística.

Aqui, ressaltamos seu papel no universo literário como a cidade de maior prestígio. $\mathrm{O}$ escritor Henri Michaux escreveu a propósito da livraria de Adrienne Monnier - um dos principais locais parisienses de consagração literária, como a pátria dos que não tem encontraram pátria,

A relação da língua francesa também está envolta em um fetiche. Prova disso, conforme elencou Casanova (2002), foram as obras de autores brasileiros, como Joaquim Nabuco, Ventura García Calderón, Castro Alves, entre outros, que chegaram a escrever suas obras em língua francesa. Machado de Assis qualificou o povo francês como o mais democrático do mundo, e com ele foram apresentados Lamartine e Alexandre Dumas ao Brasil.

Assim, associamos a geografia das grandes cidades que permitiram (re)pensar a circulação dos livros. As metrópoles escolhidas geograficamente, Buenos Aires e Paris, representadas pelas editoras independentes, corpus desta pesquisa, se tornaram centros irradiadores no cenário editorial. Por isso, destacamos a nossa segunda escolha, na Argentina, com uma editora de Buenos Aires.

Apesar dos confrontos existentes entre Brasil e Argentina, são distintas as formas como as suas histórias foram sendo constituídas, já que, segundo Fausto e Devoto (2004, p. 20). "a história de cada um dos países esteve muito mais ligada aos centros políticos e econômicos do Ocidente que entre si”. Buenos Aires, conforme afirma Muniz Jr. (2016), equivale a cerca de um terço do contingente total argentino. Essa concentração se deve à constituição histórica do país. Na capital argentina, há uma concentração de empresas e instituições culturais, com instâncias de difusão e de consagração. Como reflete o pesquisador, reiteramos o papel de Buenos Aires como uma capital editorial, já que desde o século XIX ao XX, ela tem aproximado as tendências editoriais ao padrão europeu e ao mercado de língua espanhola. Reiteramos a desproporcionalidade da capital em relação ao restante do país, que passa a ocupar aproximadamente $90 \%$ da produção editorial.

O termo usado por Muniz Jr., "capitais editoriais", vem ao encontro do que compreendemos como o funcionamento desses espaços editoriais, pois entendemos que tais escolhas -Belo Horizonte, Buenos Aires e Paris- ocupam capitais simbólicos expressivos em um cenário de publicações para mulheres, editoras, independentes - é claro que a concentra- 
ção editorial brasileira ainda está em São Paulo, por isso ressaltamos que, nessas capitais editoriais elencadas na pesquisa, existem pesos diferentes.

Com relação ao Brasil, o nosso lugar de enunciação, destacamos que a expansão do seu mercado editorial está associada à vinda da Corte para o Rio, que mais tarde, passou a ser a capital federal e tornou-se o ponto de partida do nosso mercado livreiro. São Paulo, mais tarde, prosperou economicamente e fez com que o campo editorial crescesse. Como é possível constatar, há um protagonismo editorial nas capitais paulista e fluminense, mas não podemos esquecer do lugar geográfico a que pertencemos e da marcação literária em que Minas Gerais se encontra. Por isso, enfatizamos nossa escolha para o registro de uma editora precursora no movimento de publicação afro-brasileira e fora do eixo Rio-São Paulo. Em relação à história editorial brasileira, pode-se inferir que os primeiros movimentos de publicação “independente" vieram a partir da Semana de Arte Moderna, em 1922, quando os intelectuais, como Tarsila do Amaral, Oswald de Andrade, Mário de Andrade, Manuel Bandeira, entre outros, em razão de não encontrarem uma editora capaz de acompanhar suas propostas e o conteúdo inovador de seus textos, decidiram arcar e publicar suas produções.

Com o passar dos anos, novos editores surgiram, e assim se diversificou e foram criados projetos para o mercado editorial emergente. Alguns optavam por livros didáticos ou universitários, outros editores enxergavam na literatura nacional e/ou estrangeira um grande filão. Foi nesse cenário que surgiram Saraiva, Schmidt Editora, José Olympio, Melhoramentos, Globo, Companhia das Letras, Record, Rocco, Vozes, entre outras editoras que aumentaram a bibliodiversidade - conceito que será abordado mais adiante - brasileira. Esses editores deram " $[. .$.$] continuidade a muitos projetos nascidos nas últimas décadas$ do século XIX, com traduções inéditas, capas atraentes, volumes de baixo custo [...] vários autores despontaram naquela época" (El Far, 2006, p. 44). Dessa forma, consagravam, ao mesmo tempo, quem editava suas obras.

É preciso destacar que, enquanto muitos editores viam no mercado de livros no Brasil um negócio promissor e altamente lucrativo, outros entraram no universo editorial mais interessados em levar ao público obras, autores e traduções que pudessem contribuir para o panorama intelectual brasileiro. Seriam eles chamados de uma política independente. Nesse sentido, vale a pena mencionar a atuação de Jorge Zahar e Ênio Silveira (Civilização Brasileira), que diversas vezes desafiaram os limites impostos pela ditadura militar, com o intuito de levar ao mercado obras capazes de estimular a reflexão crítica sobre a realidade brasileira. Ressaltamos no período da Ditadura Militar a atuação da editora aqui abordada, Maria Mazarello, que estava à frente da Vega Edições, em Belo Horizonte, e em sua narrativa (entrevista) destacou tal momento histórico e a sua postura como editora. Em relação aos registros de mulheres editoras brasileiras, em seu sentido curatorial, a pesquisadora Ana Elisa Ribeiro, desde 2016, busca o registro dessas mulheres de nosso país, até então pouco discutidas e até mesmo silenciadas nos estudos editoriais. Intitulada "Mulheres que editam: um mapa preliminar no Brasil”, Ribeiro (2019) busca trazer visibilidade e protagonismo a essas mulheres que editam. No levantamento realizado pela pesquisadora, destacamos alguns nomes que merecem destaque: Rose Marie Muraro e parceiras, no Rio de Janeiro, da Rosa dos Tempos, que colocaram a temática de gênero em seu catálogo, mas nem sempre em primeiro plano; Zahidé Muzart e parceiras, Elvira Sponholz e Su- 
sana Funck, que fundaram a editora Mulheres, em Florianópolis. Tal editora foi fundada em 1995, como aborda Correia e Silva (2019), todas professoras, especialistas em autoria feminina e vinculadas à linha de pesquisa "Mulher e Literatura" da Associação Nacional de Pós-Graduação e Pesquisa em Letras e Linguística (ANPOLL). Por parte dessa editora, houve uma preocupação e o compromisso com o resgate de nomes femininos na literatura nacional e internacional, revelando o papel crucial da literatura como instrumento de promoção da igualdade de gênero. A casa editorial teve aproximadamente duas décadas de atividade, com mais de 90 títulos em sua criação. No entanto, após a morte de Zahidé Muzart, em 2015, a editora continua, mas sem o mesmo fôlego. A Editora Mulheres teve o seu destaque por ser precursora na temática de gênero no Brasil.

Destacamos as editoras mulheres, mineiras, não necessariamente com publicações sobre mulheres ou sobre feminismo, mas que são editoras em seu sentido curatorial, como Rejane Dias, fundadora da Autêntica; Maria Antonieta Cunha, fundadora da Editora Miguilim; Sônia Junqueira, também autora de livros infantis, que teve vasta experiência na editora Abril e, atualmente, na Autêntica, em Minas Gerais. Curiosamente, tanto Maria Antonieta Cunha quanto Sônia Junqueira iniciaram às suas atividades editoriais a partir da década de 1960 e 70, vinculadas às publicações infantis, traço comum de editoras mulheres com essa especificidade literária, ligadas a um imaginário da docência e da educação sobre o gênero.

Novamente, destacamos a figura de Maria Mazarello, em Belo Horizonte, que fundou a Mazza Edições, a fim de publicar autores negros(as), ela mesma negra, em 1981, selecionada para esta pesquisa e que será mais detalhada.

Por fim, no contexto brasileiro, podemos admitir que uma das maiores editoras ditas de esquerda e com um vasto catálogo progressista foi idealizado e mantido, até hoje, por uma mulher editora, a paraense Ivana Jinkings. A pesquisadora Ribeiro (2019) também já refletiu ${ }^{1}$ sobre essa editora que, filha de um pai comunista, deu continuidade aos primeiros passos que a editora Boitempo, fundada pelo seu pai, sustentava. Em 1995, assume a editora, sendo hoje reconhecida pela difusão literária, marxista e progressista. Jinkings foi uma das fundadoras da Liga Brasileira de Editores (Libre).

A seguir, iremos contextualizar o histórico dessas editoras, Maria Mazarello (Brasil), Constanza Brunet (Argentina) e Paula Anacaona (França), suas trajetórias e concepções de catálogo. Como discutido por Bourdieu (2014), é pertinente pensar a relação que se pode estabelecer do editor e de sua casa editorial, que afirma existir, uma forte correspondência entre as características do editor e as características de sua editora - o que, a nosso ver, será possível fazer essa associação a partir das narrativas das editoras. Por isso, problematizaremos o lugar do independente no meio editorial e como essas editoras refletem o modo de ser da profissão.

\section{Coleta de dados}

Primeiramente, foi feito um contato prévio, por e-mail, com todas as editoras, demonstrando a intenção desta pesquisa e o papel fundamental que uma entrevista poderia sus- 
tentar ao trabalho, já que precisaríamos de dados precisos de suas narrativas e das características editoriais das empresas. As pré-entrevistas foram os primeiros passos que utilizei antes de chegar com a câmera nas mãos. Como conhecia Maria Mazarello há alguns anos, conversei com ela antes sobre a possibilidade de nos ceder fotografias, documentos, traços marcantes de sua história para o dia de nossa entrevista. E, como combinado, ela nos recebeu no jardim de sua casa, que hoje é a editora, com todo esse material. Ainda chegamos no momento em que estava separando sementes de café, com a justificativa: "[...] eu fico aqui no telefone, separando a semente boa da ruim, é uma terapia, tem horas que eu não posso falar com o autor que a obra dele tá horrivel, então eu venho aqui". A entrevista com a editora da Mazza Edições foi realizada em 2017, durando cerca de quatro horas, e aqui separamos alguns trechos que nos ajudam a retratar o seu perfil biográfico.

A entrevista com a editora Constanza Brunet foi realizada em novembro de 2019, com aproximadamente duas horas, em seu escritório no bairro Colegiales, em Buenos Aires. Bem semelhante ao local de trabalho de Maria Mazarello, em Belo Horizonte -ambas cidades que ocupam adjetivos em seus nomes- são locais cheios de árvores, fotografias, quadros ao redor das paredes ressaltando as importantes contribuições editoriais e, curiosamente, a mesma máquina de datilografar na sala das editoras.

Tendo em vista a distância de nosso lugar de enunciação -a pesquisadora em Belo Horizonte, Brasil-, não conseguimos ainda fazer a entrevista presencial com a editora francesa Paula Anacaona, em Paris, mas não houve empecilho quanto ao seu desenrolar, feito virtualmente, no decorrer de 2019.

\section{As editoras}

\section{Maria Mazarello - Mazza Edições}

Entre os critérios de escolha das editoras está, entre outros motivos já citados, a "bibliodiversidade" (Colleu, 2017). Sabemos que tal conceituação já foi discutida por outros/as autores/as, no entanto, utilizaremos essa definição de Colleu, cuja noção aplica o conceito de biodiversidade ao livro, ou seja, remete à diversidade de produções livreiras disponíveis ao público que essas editoras sustentam. A escolha de Maria Mazarello se justifica por ser uma das editoras pioneiras no Brasil com publicações voltadas à diversidade racial, com o nicho específico de publicações afro-brasileiras. Ao se referir à sua trajetória, Mazza sempre relata um problema social: o racismo. Por ser negra, mulher e pobre, enfrentou barreiras que são fortemente descritas durante sua entrevista. Reafirmamos o vínculo de seu perfil com a sua casa editorial, já que poucos a conhecem pelo nome completo; ela e a editora estão imbricadas até mesmo pelo apelido: Mazza. É assim que tanto a editora quanto a casa editorial são conhecidas e indissociáveis.

Foi pelo motivo de ser negra que fundou a sua editora, com o intuito de disseminar uma literatura diversa e formar leitores que acreditam em uma sociedade ética, justa e com liberdade de expressão. Segundo a editora, foi na Europa, durante seu mestrado em Edi- 
toração, que viu "negros de verdade" e editoras cujo objetivo era reunir autores, livros, ilustradores e personagens negros. Assim, de volta ao Brasil, na década de 1980, com a utopia de fazer uma editora voltada às publicações afro-brasileiras, justifica: “[...] eu sabia que grande eu não iria ser"; mas resolveu enfrentar essas dificuldades. De volta ao Brasil, relata o início e a trajetória de sua editora:

Evidentemente, quando eu cheguei aqui, pra tentar... Foi uma batalha. Eu sabia que grande eu não ia ser, especialmente pela linha que eu resolvi trabalhar. Foi muito difícil porque, na verdade, o Brasil e até hoje, não admite que ele é um país racista. A dificuldade minha, na verdade, como pequena editora foi desde o princípio para chegar a conseguir publicar. E ilustrador? Não tinha ilustrador negro ou ilustradora que trabalhava com a questão da negritude! Esse também foi um trabalho que a Mazza Edições fez, eu fiz muito esse trabalho. Acabou que a Mazza Edições chegou na frente, em termos de ser a primeira editora brasileira, realmente, a encarar a temática, a trabalhar na temática, na realidade. Isso, sem falta modéstia, nacionalmente o pessoal reconhece que foi a Mazza Edições que topou essa empreitada. Eu volto para o professor Edgar. Eu topei essa empreitada no fundo, no fundo, com aquela missão que o professor me deu. Ele falou assim: "Você tem que continuar o trabalho o espírito da Vega. Você é editora! Você tem que continuar! Você tem que perseguir!”

Nessa passagem, Mazza menciona o seu antigo chefe da editora Vega -responsável pela publicação de livros didáticos na década de 60 em Belo Horizonte-, como alguém de grande influência em sua vida. Nesse trecho, "você tem que continuar o espírito da Vega", percebemos um tom até confidencial, com explicações fundamentadas em uma "verdade" exterior ao sujeito, que se expressa pelas ideologias, um imaginário quase sagrado de "que existe um caminho certo, de que devemos buscar os sonhos, pois eles são possíveis".

No catálogo da editora, há mais de trinta e seis anos em atividade, encontram-se publicações nas áreas de Sociologia, Antropologia, História (sobretudo temas ligados ao Sagrado e aos movimentos sociais), Educação (com a publicação de materiais didáticos e paradidáticos), Literatura Brasileira, Literatura Infantil e Infantojuvenil. Recentemente, para atender às necessidades de publicações de diversas temáticas infantis, foi criado o selo Penninha Edições, contribuindo para a bibliodiversidade e com a chance de participação e venda em outros nichos de mercado, bem como participar de editais de incentivo à leitura pelo governo do Estado. Por fim, Mazarello nos afirma:

Eu acho que um bom editor ele, ele, além de gostar de ler, gostar de livro, ele precisa ter o feeling. Ele tem que ter um compromisso, eu diria que é quase que uma missão.

Com essa abordagem, percebemos o balanço que Mazza faz da própria vida e, sobretudo, de sua profissão. Baseado em um saber de experiência, diz que o editor precisa ter feeling, e acrescenta que é quase uma "missão", remetendo-nos a um compromisso ético em seu percurso, orientado por um imaginário de fé. 


\section{Constanza Brunet - Marea Editorial}

Tendo em vista o contraste argentino frente ao brasileiro, embora próximos geograficamente, mas com diferenças históricas significativas, tivemos o interesse em entrevistar a editora Constanza Brunet, da Marea Editorial, que tem em seu discurso uma vertente fortemente atrelada às ideias marxistas e leninistas, de apoio a movimentos sociais feministas e LGBTQIs, que são ressaltados no catálogo de sua editora. Notamos, aqui, o perfil de Constanza Brunet ligado ao imaginário da mulher argentina, com uma vertente ideológica de esquerda e politicamente engajada.

Com formação em Jornalismo e Ciências Políticas, a argentina Constanza Brunet sempre se dedicou ao jornalismo gráfico e, antes de criar a sua própria editora, começou a trabalhar com edição de livros. Deslumbrada com o ofício, criou a Marea Editorial em 2003, com publicação, de início, de jornalistas argentinos de prestígio, livros de não-ficção e ensaios. A editora já recebeu prêmios de colegas livreiros que apreciam os livros de sua casa editorial. Afirma que é um trabalho bastante solitário, pequeno e de um lugar muito artesanal, no qual se destacam a qualidade das edições, o compromisso ideológico e os valores com os temas da realidade, dos direitos humanos e da democracia. Sobre a sua profissão, relata:

Es uno de los trabajos más lindos del mundo. Los libros, para los editores que no tienen una enorme fortuna cuando comienzan o no pertenecen a un gran grupo, son todos pequeños milagros. Es muy azaroso, es muy difícil saber qué libro funciona. No hablamos de una editorial pequeña en donde todo es olfato. Uno tiene que estar produciendo y reproduciendo el milagro, siempre. Pero lo lindo es que no estás alienado del objeto de producción ${ }^{2}$.

Mais uma vez, ressaltamos a relação da profissão relaciona à vida íntima dos seres humanos. Atrelado a isso, os desafios para quem é independente, como um imaginário até de milagre para um livro dar certo.

O catálogo da editora está formado por cinco coleções que abordam gêneros de investigação jornalística, relato histórico, ensaio, narrativa e crônica. A maioria dos seus autores são jornalistas ou investigadores argentinos. Curiosamente, Buenos Aires tem grande parte de suas casas editoriais gerenciadas por mulheres ${ }^{3}$. Assim, Constanza se uniu a outras editoras para que, juntas, pudessem ir a feiras e contribuir com a distribuição de livros em outros países. Constanza também atende às publicações que abordam fatos históricos, sobretudo da história da Argentina, e temas que se relacionam a um posicionamento de esquerda. Por isso, os livros não ficcionais são os que mais vendem, segunda ela, muito a surpreendeu a vendagem desse nicho de mercado jornalístico.

\section{Paula Anacaona - Anacaona Edições}

Por fim, apresentamos editora Paula Anacaona, de Paris, que se destaca pelas publicações de livros de literatura brasileira traduzidos na França. Em 2009, inaugura a casa editorial 
que tem também o seu sobrenome. Anacaona se projeta como responsável por difundir uma literatura primorosa em ambiente europeu, marcada pela resistência e por um trabalho de difusão de ideias brasileiras, marginalizadas, para serem lidas a um público, até então, com ideias estereotipadas do Brasil. Segundo a editora:

Eu sempre gostei de literatura, quer seja francesa ou estrangeira. Quando eu comecei a me apaixonar pelo Brasil, há uns 15 anos, naturalmente eu vi que a literatura era também um bom meio para conhecer o país, também para aprender a língua, já que o português não era a minha língua "natural". Rapidamente, então, eu comecei a ler, e eu vi também que havia poucos livros traduzidos para o francês. Foi aí que surgiu a ideia de traduzir primeiro alguns livros por outra editora, e depois eu decidi montar a minha própria editora.

Dessa forma, escolhendo a profissão por meio de um desejo e de uma ambição literária e pessoal, funda a editora. Francesa, começou a aprender português aos 24 anos. Em seguida, fez dessa língua sua profissão, começando a trabalhar como tradutora em algumas casas editoriais. Em 2010, decidiu criar a sua própria editora, especializada em Literatura Brasileira, em que ela mesma conseguisse traduzir as obras. Ela garante que, se não fosse tradutora, não seria editora. Surgia, então, a editora Anacaona, com o viés de Literatura Marginal, que a comovia. Ela enfatiza que, apesar de não ser favelada, há alguma raiva ou ódio com que ela possa ter também, justificando a sua linha de publicação.

Sobre as publicações de sua editora, ela diz que faz algo como "canibalismo" no Brasil, porque considera os livros e os projetos gráficos mais bem elaborados, e volta para França com novas perspectivas de cores, projetos, ilustrações. A falta de Literatura Brasileira marginal ou de gueto foi o que também impulsionou esse tipo de publicação. O primeiro livro publicado foi algo epifânico: "eu li e no dia seguinte mandei um e-mail para o autor, e foi assim para muitos livros. Cada livro é como meu filho". Pelo menos uma vez ao ano, Paula Anacaona viaja ao Brasil em busca de suas publicações e do contato com os autores, vai a sebos, livrarias, tem uma escuta atenta ao que os leitores dizem. Reforça o papel dos agentes, mas faz questão de ir ao sebo e publicar um autor que ninguém conhece ainda na França: "eu quero autores mais marginais".

Ela relata o imaginário do brasileiro e do Brasil na França, ligado ao preconceito e aos estereótipos (mulher, futebol e samba), mas é por isso que insiste em um outro lado de publicação, procurando desmitificar esses imaginários já cristalizados no meio social francês. Alguns livros de autores já consagrados foram traduzidos para o francês, como José Lins do Rego, Lima Barreto, e a editora entendeu que teria um nicho de mercado, teria um público na França, que poderia publicar e ter leitores. No início, publicou especificamente a linha marginal, entre Rio e São Paulo, mas depois decidiu mudar, pois percebeu que era clichê. $O$ francês já conhecia a favela, então ela começou a publicar autores de outras regiões do país. Assim, diversificou suas publicações em três selos, divididos em urbano, terra e época. Com isso, acredita que abarca grande parte da literatura que é produzida, hoje, no Brasil. Publicou nomes como Conceição Evaristo, autores que abordam mulheres marginalizadas, negras, autoras do Nordeste brasileiro, castigadas pela seca e pelo aban- 
dono social. Também autores como Rachel de Queiroz, Carolina Maria de Jesus, Maurício Negro, que simbolizam a proposta de sua editora.

A seguir, iremos trazer a discussão que norteia a nossa proposta: as imagens de si-o ethos discursivo- que essas editoras projetam de si.

\section{As imagens de si: o ethos}

Para demonstrar essas versões de si ressaltadas durante as entrevistas com as editoras, partimos do conceito teórico-metodológico de ethos discursivo.

Todo ato de tomar a palavra implica a construção de uma imagem de si. Assim, não é necessário, segundo Amossy (2005), que o locutor faça um autorretrato. Para a sua representação, "basta seu estilo, as competências linguísticas e enciclopédicas, as crenças implícitas" (Amossy, 2005, p. 9). Essa representação de si é o que iremos contextualizar: o ethos. É pertinente voltarmos ao conceito de ethos pensado por Aristóteles que, a partir da retórica antiga, trouxe a tríade do ethos, pathos e logos. Essas três provas empregadas pelo orador para persuadir seu auditório são caracterizadas por: i) ethos: o caráter do orador; ii) pathos: paixões despertadas no ouvinte; iii) logos: o próprio discurso. Para Maingueneau (2008), 'os 'argumentos' correspondem ao logos, as 'paixões' ao pathos, as 'condutas' ao ethos" (Maingueneau, 2008, p. 14, destaques do autor).

A elaboração da noção contemporânea de ethos que abordamos atualmente se deve a Dominique Maingueneau. Para o autor, essa noção se desenvolve de forma articulada à de cena de enunciação. Para o pesquisador, o ethos está ligado à enunciação, não a um saber extradiscursivo sobre o enunciado, que irá se desdobrar no registro do mostrado e do dito. Nesse sentido, o público constrói representações do enunciador antes mesmo que ele fale. É por isso a primeira distinção que Maingueneau faz acerca do ethos discursivo e do ethos pré-discursivo. O primeiro se refere à noção aristotélica, pela qual o autor se volta à atenção. O fato de um co-enunciador não saber, previamente, o caráter do enunciador, não significa que ele não saiba, por exemplo, em qual gênero discursivo pertença ou a um certo posicionamento ideológico. Em termos pragmáticos, "o ethos se desdobra no registro do 'mostrado' e, eventualmente, no do 'dito'” (Maingueneau apud Amossy, 2004, p. 70).

O termo tom também é utilizado para a conceituação sobre o ethos. Até em um texto escrito, existirá uma vocalidade específica que permite relacioná-lo a uma fonte enunciativa. $\mathrm{O}$ autor ressalta que a vocalidade implica uma determinação do corpo do enunciador. Assim, a leitura faz emergir uma origem enunciativa, uma instância subjetiva encarnada que exerce o papel de fiador. Esta figura o leitor quem deve construir, com base em indícios textuais, sendo investido de um caráter e de uma corporalidade. A qualidade do ethos remete à figura do fiador que, mediante sua fala, se dá uma identidade compatível com o mundo que se supõe que ele faz surgir em seu enunciado. (Maingueneau, 2004).

Portanto Maingueneau afirma que o enunciado se dá pelo tom de um fiador associado a uma dinâmica corporal, sendo que o leitor não codifica o sentido, mas participa, fisicamente, do mesmo mundo do fiador: 
O co-enunciador captado pelo ethos, envolvente e invisível, de um discurso, faz mais do que decifrar seus conteúdos. Ele é implicado em sua cenografia, participa de uma esfera na qual pode reencontrar um enunciador que, pela vocalidade de sua fala, é construído como fiador do mundo representado. (Maingueneau, 2004, p. 90).

Por outro lado, Maingueneau (2008) pondera que, apesar de o ethos estar ligado fortemente ao ato de enunciação, ele existe antes mesmo que o enunciador fale. Assim, há o ethos discursivo e o thos pré-discursivo.

- o ethos é uma noção discursiva, ele se constrói através do discurso, não é uma "imagem" do locutor exterior a sua fala;

- o ethos é fundamentalmente um processo interativo de influência sobre o outro;

- é uma noção fundamentalmente híbrida (sócio-discursiva), um comportamento socialmente avaliado, que não pode ser apreendido fora de uma situação de comunicação precisa, integrada ela mesma numa determinada conjuntura sócio-histórica. (Maingueneau, 2008, p. 17, destaques do autor).

\section{O ethos discursivo das editoras}

A partir das entrevistas realizadas com as editoras e o histórico da trajetória profissional que as editoras sustentam há anos, trouxemos alguns possíveis ethé que elas demonstram no e pelo discurso. Para isso, trabalhamos em torno da adjetivação (competência, independência e resistência) que caminham em consonância ao que ambicionam e transmitem a partir do catálogo de suas casas editoriais.

\section{Ethos de competência}

Exige saber e habilidade, um domínio particular na atividade que exercem. Características que invocam esse percurso: herança, estudos, funções exercidas, experiência adquirida. Mazza, Constanza e Paula assumem a competência por terem um papel decisivo na cadeia editorial e um compromisso profissional de se aperfeiçoar e buscar a melhoria das produções, atrelado a uma característica "independente".

\section{Ethos de independência}

Como já apontado, a ideia emblemática do "independente" está associada a diferentes características para cada editora. Em Mazza, percebemos a imagem de independente atrelado a um perfil militante. Embora tenha sido uma batalha conseguir abrir uma editora independente, persiste em continuar com publicações voltadas à temática afro-brasileira, motivada pela sua trajetória de vida, como na afirmação: 
Um bom editor ele não publica qualquer coisa... ele... Ele... Acerta e erra... Porque a gente não tem bola de cristal, o dinheiro, na verdade, não pode tá num primeiro plano. Eu vou publicar isso aqui porque isso vai vender. Então, eu acho o seguinte, essa visão não é a visão de um bom editor (Maria Mazarello, 2017).

Em Constanza, o ethos independente está associado à precursora na temática progressista, de esquerda na Argentina e como uma mulher legitimada (jornalista e cientista política) para tal abordagem. Em nossa entrevista realizada com Brunet, ela afirma:

Las editoras independientes surgen en contraposición a este monopolio de grandes grupos concentrados, absorviendo editoriales y es muy difícil para bibliodiversidad. Creo que las independientes son las editoras que el criterio de lucro no es el mayor (Constanza Brunet, 2019).

Por fim, em Paula Anacaona ressaltamos o ethos independente ligado à questão de subverter estereótipos brasileiros na França, de uma busca para difundir uma literatura verdadeiramente brasileiro aos franceses, como na abordado a seguir:

Os livros que eu vendo muito são os livros sobre favela, porque eu sei, de um ponto-de-vista comercial, que o título é bom, que o francês gosta da favela... assim meio exótico. Eu espero atrair ele com esse título mas eu acredito que, depois, o que tem dentro vai desfazer um pouco esse preconceito e ele vai ter mais a imagem da favela e menos a imagem da Globo. O meu trabalho realmente é um pouco pisar em ovos, no sentido de que os franceses têm uma expectativa, e eu não posso decepcionar. A ideia é equilibrar essa expectativa com uma ética profissional, que é mostrar o Brasil como eu conheço e como eu amo (Paula Anacaona, 2019).

\section{Ethos de resistência}

O ethos que emerge das práticas discursivas das três editoras está atrelado à resistência, marcada por uma busca das editoras de que suas produções sejam respaldadas por valores literários e artísticos das obras, pela busca de um público leitor e de sua formação crítica, resistindo à vinda dos oligopólios (Constanza Brunet), do preconceito existente na sociedade (Maria Mazarello), a busca de uma literatura nacional e desmistificar estereótipos do Brasil a outros países (Paula Anacaona); Em Constanza, "La resistencia entre los independientes en la Argentina es muy importante. Hay mucha producción, pero es muy dificil distribuir, exibir". As posturas das editoras geram alguns efeitos de sentido, como a força e a coragem, já que, apesar de terem enfrentado diversos percalços em suas vidas, resistem e persistem, utilizando-se dessa característica como resposta para seguir a caminhada. Nos próximos tópicos, abordaremos a discussão sobre o que é ser independente nesse campo editorial. 


\section{Editando: as versões do independente}

Como Muniz Jr. (2016) aponta, a noção de editor independente ampliou sua presença nos relatos de vida cultural nos últimos vinte anos. Tal presença se deve ao surgimento dos grandes grupos editoriais que seguem outra lógica de funcionamento de uma editora convencional. Observam-se, então, várias dicotomias nesse espaço editorial. De um lado, temos as pequenas editoras, de capital familiar, do livro com qualidade literária; de outro, as grandes, com capital financeiro e o livro como mercadoria. Em meio a essas polarizações, Muniz Jr. (2016) propõe classificações em torno do independente.

O título de sua tese, Girafas e Bonsais: editores independentes na Argentina e no Brasil (1991-2015), já expressa essas duas categorias dentro do universo independente. Assim, o pesquisador propõe a dualidade dos editores "girafa", editores empresários culturais, que "mantêm a cabeça no alto e os pés no chão" (Muniz Jr. 2016, p. 19), caracterizados, geralmente, por editores mais velhos, e os editores "bonsai", aqueles editores que "requerem muitos cuidados e estão fadados a nunca crescer” (Muniz Jr. 2016, p. 19). Esses últimos permanecem com um catálogo pequeno e não têm pretensão de virar empresa, fazem livros nas horas vagas, como um hobby, sendo caracterizados como editores mais jovens. Dessa forma, ao unir os dois lados (a empresa e a simples casa editorial), ambas do universo independente, José Muniz Jr. tenta nortear os perfis editoriais escolhidos em sua pesquisa e, com isso, deixa margens para pensar, neste trabalho, mais uma categorização, para um possível nível intermediário entre girafas e bonsais, cuja pretensão é o equilíbrio de uma casa editorial, que não se deve estagnar nem ter ambições gigantescas que não se poderá cumprir. Com a escuta atenta às editoras, Maria Mazarello, Constanza Brunet e Paula Anacaona, entendemos que todas estão em um nível intermediário, entre essas girafas e entre os bonsais, já que conseguem conciliar os interesses editoriais, as suas apostas, as ideologias, contendo os sonhos.

\section{Os critérios de solidariedade entre as editoras independentes}

Como vimos em José Muniz Jr., é possível estabelecer um diálogo entre as variações do universo independente. Percebemos a coletividade com que estão, sobretudo, inseridos os "bonsais" (fadados a nunca crescer), que também precisam das "girafas" (empresários culturais, cuja ambição é grande) para divulgação de suas obras. Afinal, ambos estão inseridas em um contexto de paixão pelos livros.

Em consonância com a perspectiva de Muniz Jr., para o professor José Luís de Diego não existe uma definição de editor independente por si só ${ }^{4}$. Certamente, em seu ponto de vista, escolher se tornar editor de cunho independente está indissociável de uma relação vocacional com a cultura, a literatura e a filosofia. Como independente é uma definição ideológica, difícil de ser demonstrada, poderíamos direcionar um olhar aos fatos que ocorreram na América Latina, Europa e Estados Unidos, com a vinda de conglomerados mercadológicos que monopolizam o mercado editorial. São grandes empresas que acabaram por comprar ou extinguir as editoras que se voltavam à publicação direcionadas à bibliofilia. 
Existe um campo lexical atrelado ao independente, como o alternativo, o indie, o cult, o artesanal, mas é preciso separá-las, apesar de inseridas em um mesmo conjunto heterogêneo. Podemos afirmar que, em comum, todo o léxico está associado à vanguarda, fora do eixo totalmente comercial. As editoras independentes, como De Diego refere, têm aqueles editores "duas caras", metáfora para os dois lados em questão: o dinheiro e a cultura. Um dos critérios distintivos que permitem a resistência dos independentes é a solidariedade. Nesse sentido, traçaremos os critérios de solidariedade respaldados pelas editoras que integram uma rede independente:

1. Organização de feiras independentes, como é o caso da feira do Feria de Editores (Argentina), feiras Plana, Miolo(s), Tijuana e Parque Gráfico (Brasil), Feira Textura e Faísca (Brasil - Belo Horizonte);

2. Distribuição entre os países - no contexto dos países latinos, como a Argentina, Uruguai e Chile, esse diálogo é ainda maior pela facilidade da língua. Solidariedade comercial e cultural;

3. Buscam-se livros menos conhecidos, autores menos famosos, excluídos ou convidados, que não tiveram oportunidade no circuito editorial;

4. Vendas em sites e blogs, que recomendam outras editoras interligadas, que podem oferecer outros títulos específicos.

5. Sugestões de publicação e de troca de originais entre as editoras.

Embora seja emblemática uma conceituação em torno do independente, acreditamos que as três editoras estão inseridas em uma rede de solidariedade. Isso porque consideram o surgimento de novas empresas como um feito que assegura a continuidade de um projeto cultural em que se pesam mais intenções comuns do que as nuances diferenciais. Por um lado, podemos afirmar, a partir de Botto (2014), que as editoras independentes tiveram um apogeu a partir da década de 90, com características de serem entidades especializadas e com viés democrático, que apontam um segmento do público leitor específico e promovem gêneros e títulos que as grandes empresas multinacionais descuidam. Por outro lado, a categoria dita independente engloba projetos bem diversos, o que sugere a tal definição "independente a respeito de quê?". Botto (2014) coloca o questionamento e, para tentar respondê-lo, remete aos estudos de Hermán Valoni (2010), que irá definir essa característica das editoras por meio de seus editores. Para isso, analisa as decisões de publicação e critérios comerciais para afirmar que esses editores têm um "romantismo revolucionário", combinam a figura do escritor com a do militante e o editor como criador de espaços culturais, conforme demonstrado nas três mulheres editoras, corpus desta pesquisa.

\section{Considerações finais}

Caminhando para finalizar nossas proposições, observamos que, por meio das narrativas de vida das editoras, percebemos que as escolhas profissionais foram guiadas por algo que as próprias editoras colocaram como algo utópico. A escolha para a profissão de editora, 
ora ao acaso, como em Mazza, ora por um interesse, como em Constanza e Paula, são marcadas pela utopia, numa tentativa de mudar o cenário editorial.

Neste artigo, a partir as projeções de si ressaltadas pelo ethos discursivo das editoras, nosso intuito foi de demonstrar as inúmeras vozes de editoras que, até então, em nosso histórico editorial, foram silenciadas pelo simples fato de serem mulheres. São décadas de produção editorial marcadas por autores(as) relevantes, precursoras de temáticas sociais. Embora não sejam as editoras reconhecidas por publicar feminismo(s), podemos relacionar a postura do gênero atribuído a um papel social ainda pouco discutido. Seguimos o percurso dessa pesquisa, ambicionando encontrar ainda mais editoras mulheres, que corroboram à postura crítica, editorial, literária e revolucionária da sociedade.

\section{Notas}

1. Ribeiro, A. (2019). Boitempo editorial e Ivana Jinkings: um quarto de século de uma editora de esquerda no Brasil [Web Page]. Retrieved from https://www.revistas.uneb.br/ index.php/pontosdeint/article/view/7017/4627

2. Tradução nossa para: "É um dos trabalhos mais bonitos do mundo. Os livros, para editores que não têm uma enorme fortuna quando começam ou não pertencem a um grande grupo, são todos pequenos milagres. É muito aleatório, é muito difícil saber qual livro funciona. Não estamos falando de uma pequena editora onde tudo é cheiro. É preciso sempre produzir e reproduzir o milagre. Mas o bom é que você não está alienado do objeto de produção".

3. Digena, D. (2016). Editoras de libros: un terreno donde ellas son más y están dejando huella [Web Page]. Retrieved from https://www.lanacion.com.ar/cultura/editoras-de-li bros-un-terreno-donde-ellas-son-mas-y-estan-dejando-huella-nid1877720

4. Informação verbal. Reflexões feitas pelo professor José Luís de Diego (Universidade de La Plata), durante minicurso em junho de 2017 no CEFET-MG.

\section{Referências}

Amossy, R. (org). (2005). Imagem de si no discurso: a construção do ethos. São Paulo: Contexto. Arfuch, L. (2010). O espaço biográfico: dilemas da subjetividade contemporânea. Trad. Paloma Vedal. Rio de Janeiro: EDUERJ.

Botto, M. (2014). 1990-2010: concentración, polarización y después. In: De Diego, José Luis. Editores y políticas editoriales en Argentina (1880-2010). Buenos Aires: Fondo de Cultura Económica, p. 1-29.

Bourdieu, P. (1999). Uma revolução conservadora na edição. Política \& Sociedade, v. 17, n. 39, p. 198-249. mai./ago. 2018. [Trad. Luciana Salazar Salgado e José de Souza Muniz Jr. Originalmente publicado em Actes de la recherche en Sciences Sociales, v. 126-127, p. 3-28, mars] 
Bourdieu, P. (2014). Una revolución conservadora en la edición. In: Intelectuales, política y poder. Eudeba: Buenos Aires.

Casanova, P. (2002). A república mundial das letras. Trad. Marina Appenzeller. São Paulo: Estação Liberdade.

Colleu, G. (2007). Editores independentes: da idade da razão à ofensiva? Trad. Márcia Atálla Pietroluongo. Rio de Janeiro: Libre - Liga Brasileira de Editoras, 120p.

Correa e Silva, L. (2019). "Um sonho possível? Editora Mulheres e o feminismo editorial no Brasil: um tributo à Zahidé Lupinacci Muzart2. Disponível em: <encurtador.com. br/ckKZ1>. Recuperado em 16 dezembro, 2019.

Elfar, A. (2006). O livro e a leitura no Brasil. Rio de Janeiro: Jorge Zahar Ed.

Muniz Jr, J. de Souza. (2016). Girafas e bonsais: editores "independentes" na Argentina e no Brasil. 2016, 335f. Tese (Doutorado em Sociologia), Programa de Pós-Graduação em Sociologia da Faculdade de Filosofia, Letras e Ciências Humanas, Universidade de São Paulo, São Paulo

Ribeiro, A. E. (2018). “O apagamento das mulheres editoras”. In: Itinerários, Araraquara, n. 47, p. 229-232, jul./dez. Recuperado em 16 dezembro, 2019.

Ribeiro, A. E. (2019). "Editoriales y editoras en Brasil hoy. Dos casos contemporáneos: Chão da Feira y Relicário”, Lectora, 25: 227-240. ISSN: 1136-5781 D.O.I.: 10.1344/Lectora 2019.25.14.

Ribeiro, A. E. (2019). "Boitempo editorial e Ivana Jinkings: um quarto de século de uma editora de esquerda no Brasil”. Pontos de Interrogação, v. 9, n. 1, jan.-jun., p. 201-226.

Thompson, J. B. (2013). Mercadores de cultura. São Paulo: Editora Unesp.

Resumen: Tenemos la intención de analizar el discurso autobiográfico de tres editoras de libros independientes, mujeres, en la posición de creadores de sus editoriales y creadores de catálogos. A través de un discurso de Constanza Brunet (Editorial Marea - Argentina), Maria Mazarello (Mazza Edições - Brasil) y Paula Anacaona (Anacaona Edições - Francia), pretendemos encontrarnos como proyecciones del yo y la idea del trabajo como algo íntimo e inseparable de ser humano.

Palabras clave: Mujeres editoras independientes - Mercado Editorial - Ethos - Maria Mazarello - Constanza Brunet - Paula Anacaona.

Abstract: We intend to analyze the autobiographical discourse of three independent book publishers, women, in a position of creators of their publishing houses and of the catalog itself. Through the speech of Constanza Brunet (Marea Editorial - Argentina), Maria Mazarello (Mazza Edições - Brazil) and Paula Anacaona (Anacaona Edições - France), we intend to find the projections of the self and the idea of work as something intimate and inseparable from being human. 
Keywords: Independent publishers - Editorial Market - Discursive Ethos - Maria Mazarello - Constanza Brunet - Paula Anacaona.

[Las traducciones de los abstracts fueron supervisadas por el autor de cada artículo] 